\title{
Construct Validation of a School Principal Decision-Making Styles Scale
}

\section{ABDULHAKAM HENGPIYA}

Universiti Utara Malaysia

\begin{abstract}
Whereas substantial research in decision-making styles has focused on the theoretical and conceptual definitions, relatively less empirical attention has been paid to the development of its measures. Thus, the purpose of this study is to develop and validate a measure of school principal decision-making styles based on Vroom and Yetton's (1973) theoretical framework. The researcher initially developed a 40-item pool of the Principal Decision-Making Styles Scale (PDMSS), and then these 40 items were reduced to 27 items after experts' examination of its content validity. These 27 refined items were administered to 120 primary school principals in the northern states of Malaysia. In order to examine the construct validity of the PDMSS, a factor analysis employing principal component extraction procedures with varimax rotation was used. The factor analysis resulted in a 19-item instrument that measures three extracted decision-making styles, namely, autocratic, participative, and delegation. Additionally, the item analysis showed acceptable internal consistency reliability for the overall and the three specific sub-scales of PDMSS. Moreover, the confirmatory factor analysis revealed that the three identified styles indicate a good model fit.
\end{abstract}

\section{INTRODUCTION}

Research suggests that decision-making is one of the salient factors upon which the survival of any organization is based. In this respect, Dunham (1995) asserts that the well being of all the school community's members, and the survival of the school heavily depended upon the decision-making skills of managers. For this reason, the most critical task in an organization is the process of deciding a desirable course of action to respond to encountered problems and opportunities. George and Jones (2000) explain that good decisions result in a course of action that helps the individual, group, or organization to be effective. Therefore, managers in 
educational organizations should have a profound knowledge of decision-making, and be able to make effective decisions. This is because, according to Nelson and Quick (2009), "the success of any organization depends on managers' abilities to make effective decisions" (p. 323).

Believing that decision-making style is one of the determinant variables that appears to have potentially serious consequences for overall school performance, a principal must be able to choose a specific style in order to attain the desired consequences. Because there is no one style that is best for all situations, identifying various decision-making styles and developing skills in the selection of an appropriate style need to be emphasized; when the decision-making styles are not accurate, the consequences can be quite serious. The style of decision-making depends on the leaders' choice. Effective leadership depends on understanding the context in which a certain problem surfaces. Having sufficient understanding of the context will positively help in correctly assessing how much, and what form of participation is required (Ubben, Hughes, \& Norris, 2001). Given that, inappropriate response to the demands of a situation may have a negative impact on teachers' personal satisfaction and may consequently affect their commitment.

The decision-making model which is based on Vroom and Yetton's study (1973), describes principals as having a set of leadership behaviors which can be selectively used according to the nature of the situation they are dealing with. If the situation calls for improving teachers' and students' performance, it is useful to involve them in the decision making process. Consequently, teachers and students will become more committed to their jobs (Bogler, 2001). Creating a participative atmosphere is likely to bring about effective performance for the learning and teaching, and achievement outcomes (Edwards, 2004).

Owing to the fact that decision making is one of the major determinants of organizational success as previously stated, interest in studying decision-making is growing increasingly. In spite of the presence of substantial studies that addressed developing theories on decision-making styles, there is still a dearth of research that is devoted to developing measures of decision-making styles in these theories. The researcher believes in the argument made by Schwab (1980) that theoretical progress can be hardly achieved without adequate measures (as cited in Scott \& Bruce, 1995). Therefore, this study is very significant in that it attempts to develop a psychometrically 
sound instrument for measuring principal decision-making styles that is based on Vroom and Yetton's (1973) decision-making model.

\section{DECISION-MAKING MODELS}

Research suggests that there are a variety of decision-making models which are different in their approaches and emphases. Some researchers, such as Jung (1971), Myers (1975), and Myers and McCaulley (1985), proposed a model of how representatives of each personality type (i.e., sensing, intuition, thinking, and feeling) might respond to a particular work situation. Other researchers, such as McKeeney and Keen (1974), Harren (1979), and Hunt, Krzystofiak, Meindl, and Yousry (1989), concentrated on qualitative differences in how individuals gather and process information, and arrive at a conclusion. There are also other models which are concerned with the use of cognitive complexity notions, such as information overloads, in describing decision-making styles which refer to the number of solutions and the amount of information used (Driver \& Mock, 1975). Additionally, Maier and Gertrude (1982) proposed a decision-making model that emphasized the need for individuals to consider whether to achieve decision quality or decision acceptance. Furthermore, other researchers (e.g., Tannenbaum \& Schmidt, 1973; Vroom \& Yetton, 1973; Hoy \& Tarter, 1993) proposed a model that provides guidance in the decision making process, and which describes in a continuum line how people are involved in this process.

Pondering over the previous studies, it is evident that they mostly proposed and explained their respective concepts and models of decision-making styles. However, they did not develop any instruments to measure the decision-making styles. Reviewing the literature, the researcher found out that there is dearth of research on developing instruments that measure decision-making styles. There are only two related studies that develop decision-making style instruments. The first study was carried out by Friedman (1985) who developed a questionnaire on the decision-making style of school principals. The questionnaire was based on Vroom and Yetton's (1973) concept of decision processes. However, Friedman (1985) did not focus on measuring decision-making styles; he listed items that were related to different school situations such as (1) determining rules and regulations regarding discipline problems 
at school, (2) determining the character of classroom activities, (3) choosing the textbooks that will be used in the next year from the list of approved textbooks, (4) determining the date for faculty meetings at school, and (5) allotting lab or computer time to each class. These items are rated on 4 scales. These scales are ranged, according to Vroom and Yetton's (1973) decision processes, from no subordinate involvement to high subordinate influence (e.g., $1=$ makes own decisions without consulting with subordinates; $2=$ consults with subordinates but makes own decisions; $3=$ makes joint decisions with subordinates; $4=$ delegates authority to subordinates). The second study was conducted by Scott and Bruce (1995) who developed a measure of decision-making style. Its items were written to assess rational, avoidant, intuitive, and dependent decision-making styles. Sample of items included (1) my decision making requires careful thought, (2) when I make a decision, I trust my inner feelings and reactions, and (3) I often make impulsive decisions.

Reflecting on the two studies, the researcher started to believe that it is significant to develop a new instrument that measures the rating scale used by Friedman (1985) himself, and to also develop a more specific measure of decision-making style because the instrument developed by Scott and Bruce (1995) is too general to measure decision-making styles of school principals. Therefore, this new instrument can fill the existing gap in the field of education, and serve as an inspiration for future research.

Although there are several decision making models as previously stated, Vroom and Yetton's (1973) model is used in the present study. The researcher believes in the argument that this model offers an essential manual to guide principals in selecting an appropriate decision-making style (Ubben et al., 2001). Additionally, the model is very much relevant to the field of education because it is intended to instruct school's administrators on when and how to involve others in decision-making (Ubben et al., 2001). Moreover, the model enables principals to select the most effective ways that can maximize feasible decisions. This can take place by making the principals answer several questions arrayed on the decisionprocess flow chart. Furthermore, Vroom and Yetton's (1973) model still reflects how the decision making process varies from low to high involvement in the current decision making practices in our educational environments. The model can also give us a wide and vivid picture about the reality of decision-making behavior in terms of the degree of involvement in making decisions. 
Although Vroom and Yetton's ( 1973) model was proven to be effective in the decision making process, most of the previous studies conducted based on this model tried to make refinements and enhancements in the original model (Vroom \& Jago, 1988); and had examined the relationships between this model and Myers's (1975) model (Schweiger \& Jago, 1982), and explained Vroom and Yetton' (1973) model (Pashiardis, 1993; Ubben et al., 2001; Owen, 2004). However, none of these previous studies, except Friedman's (1985) study, have developed an instrument based on this model. The researcher in this study has proposed a new instrument that is based on Vroom and Yetton's (1973) model.

\section{VROOM AND YETTON'S (1973) DECISION-MAKING MODEL}

Vroom and Yetton (1973) proposed a series of procedures for making decisions, ranging from a unilateral directive decision by the leader without input, to highly participatory forms of decisionmaking. According to Vroom and Yetton (1973), the problem for the leader is to analyze the contingencies in each situation, and then behave in the most effective manner. Their model assumes that there is no one single best style of decision-making that fits all situations. Having said that, the model provided a basis for choosing the decision process most likely to result in a maximum feasible decision (Ubben et al., 2001).

The principal decision-making styles can be assessed by the amount of opportunities a principal gives to teachers so that they are able to get involved in school decision-making processes, extending over a single continuum line in which four decision-making styles are identified (Vroom \& Yetton, 1973). These four styles are briefly described below.

\section{Autocratic Decision-Making}

Autocratic decision-making is when the manager does not consult any of the group members and comes up with the final decision alone (Bogler, 2001). In the autocratic process, Vroom and Yetton (1973) is of the view that "the manager makes decisions on matters within his/her area of freedom, issues orders or directives to his/her subordinates, and monitors their performance to ensure conformity with these directives" (p. 10). In Nye \& Capelluti (2003), an 
autocratic decision is strictly taken only by principals without consulting other interested personnel. In other words, these types of principals tend to solve their problems relying mainly on the information they have. By doing so, they maintain total control of the decision making process.

\section{Consultative Decision-Making}

Vroom and Yetton (1973) view consultative decision-making as the process when managers share the problem with their subordinates, get their ideas and suggestions, and then make decisions which may or may not reflect the influence of their subordinates. Arguing in the same line, Gallagher (2002) contends that consultative decision making takes place when managers ask employees for their ideas. He further argues that employees can influence the decision making process by the valuable information they have, and the practical alternatives they suggest. However, Gallagher (2002) points out that it is the managers who make the final decision.

\section{Group Decision-Making}

Group decision-making is when the manager shares the problem with his/her subordinates, and together they analyze the problem and obtain a mutually agreeable solution (Vroom \& Yetton, 1973). In other words, it is a style by which members of a certain group of people come to an agreement on a certain issue. The input and ideas of all the group members are discussed in order to arrive at a consensually final decision. Bogler (2001) postulates that a group decision is arrived at "when the manager discusses the problems with other members and together they come up with a final decision, in which each has had some influence" (p. 665).

\section{Delegation Decision-Making}

Delegation decision-making is when the manager delegates a problem to his/her subordinates, provides them with any relevant information that he/she possesses, and entrusts them the responsibility for solving the problem by themselves (Vroom \& Yetton, 1973). In such a situation the decision-making is done by someone other than the manager (Bogler, 2001). Therefore, the delegates' task is not just to simply read instructions, but they also have the authority to react to situations without referring back to their manager (Blair, 2004.).

Pondering over the previous four styles, it is logical to wonder: which style is the best? Vroom and Yetton (1973) answer such a question, and propose that in order to successfully select an 
appropriate decision-making style, a manager needs to raise and answer different diagnostic questions. A sample of these diagnostic questions is as follows: "If a decision was accepted, would it make a difference which courses of action were adopted?" If not, then the following question is raised: "Is acceptance of decision by subordinates critical to effective implementation?" Vroom and Yetton (1973) propose that if the answer is negative, then the use of autocratic decision is logical.

Owing to the systematic nature of the decision-making process, Vroom and Yetton's (1973) model has become very meaningful and very much relevant to teaching principals about when to adopt the different decision-making styles.

\section{OBJECTIVES OF THE STUDY}

Substantial studies have focused on the conceptual and theoretical definitions of the decision-making styles, yet less attention has been paid to the study of their psychometric properties. The lack of a psychometrically sound instrument for measuring decision-making styles may hinder researchers who are interested in decision style research and its theoretical progress. Accordingly, the present study attempts to develop a school principal decision-making styles scale (PDMSS) that is based on Vroom and Yetton's (1973) theoretical framework. To assess the construct validation of the scale, face validity and factorial validity were conducted.

\section{METHOD}

\section{Sample}

The subjects were 120 primary school principals in the northern states of Malaysia, who were enrolled in a special graduate program for headmasters at Universiti Utara Malaysia (UUM). The program is meant to qualify these principals to obtain a degree in educational management. This sample included $72(60 \%)$ males and $48(40 \%)$ females. Thirteen $(10.8 \%)$ of the subjects were between $40-44$ years old, while 58 (48.3\%) of them were between 45-48 years old, and 49 $(40.8 \%)$ of them were between $49-52$ years old. As far as their years of experience is concerned, 53 (44.2\%) of the principals had between 1-5 years experience in school principalship, 34 (28.3\%) had 6-9 
years experience, $27(22.5 \%)$ had 10-13 years experience, and 6 (5.0\%) had 14-17 years experience. The mean age and experience were 47.68 and 6.86 , respectively.

\section{Item Development Process}

In developing items to measure the proposed construct, the question of content validity is deemed critical. The items that were generated must tap the construct or measure the underlying concept being studied. The following steps, which are based on DeVellis's (2003) guidelines in scale development, were used in the item development process.

\section{Determine Clearly what Construct is to be Measured}

Items were generated after being clear about what styles of decisionmaking to include in a measure, and this was followed by a clear formulation of the conceptual definition of decision-making styles. Although several decision-making styles were identified from the literature, four styles of decision-making (i.e., autocratic, consultative, group and delegation) as proposed by Vroom and Yetton (1973) were examined in this study.

Operational definitions for the terms used in this study are as follows: autocratic decision-making refers to the context where a principal does not consult his/her subordinates, and comes up with the final decision alone; consultative decision-making refers to the situation in which a principal consults his/her subordinates but he or she makes the final decision alone; group decision-making describes the situation in which a principal and his/her subordinates discuss, analyze and make a mutually agreeable decision for an emerging problem; as for delegation decision-making, it refers to the context in which subordinates are given full autonomy, and delegated by their principals to make decisions themselves.

\section{Beginning the Process of Writing Items}

At this point, the researcher paid less attention to item quality than merely expressing relevant ideas so that the content of each item should primarily reflect the behavior of interest. Thinking clearly about the content of each style in a scale, the researcher then began writing several statements that capture the phenomenon of interest in different ways. In developing a scale, items without redundancy seem to be impossible because they express a similar idea in somewhat different ways. DeVellis (2003) asserts that "by using multiple and 
seemingly redundant items, the content that is common to the items will summate across items while their irrelevant idiosyncrasies will cancel out. Without redundancy, this would be impossible" (p.65). Two items, such as "delegate decisional responsibilities to teachers" and "transfer my decisional role to teachers" may be usefully redundant because they convey the same content reflecting "delegation decision-making" in somewhat different statements. Besides items that were self-developed, other items were derived from the taxonomy of decision processes proposed by Vroom and Yetton (1973). These items are G9, G10, and G11 (see Table 1) that tap "group decision-making". A 40-item pool of the PDMSS was generated first.

\section{3. $\quad$ Content Validity of the Scale}

The above 40-item scale was evaluated for its content validity by a panel of nine experts. These experts are $\mathrm{PhD}$ degree holders, assistant professors, associate professors, and professors, who have vast experience in supervising students and research in the area of education. The experts were asked to rate how relevant they think each item was to what the researcher intended to measure. The researcher also asked for their comments about the scale with the view of improving it. It was reported that there was a logical tie between the items of the instrument and their purpose. However, the deletion of some items was necessary because of bad items characterized by the lack of clarity due to wordiness and ambiguous meanings. Some of the items were reworded according to the experts' suggestions. Other items were merged into one item due to insignificant item redundancy, for example, having an item in the initial scale which said "seek ideas and advice from teachers before deciding" was of little advantage in the presence of another item that stated "consult teachers when making important decisions". These two items were merged into a single item that read, "seek advice from teachers when making important decisions". After item deletion and refinement, 27 items of the PDMSS were retained. These items were rated on a scale of 1-7 $(1=$ never, $2=$ rarely, $3=$ occasionally, $4=$ sometimes, $5=$ often, $6=$ most of the time, and $7=$ always).

\section{Construct Validity of the Scale}

To examine construct validity of the scale, four expert judges (i.e., two professors and two $\mathrm{PhD}$ degree holders with extensive experience in research as demonstrated by their research publications 
in the area of education) were asked to examine whether the 27item scale accurately represented the different styles of decisionmaking. In this process, they were given the working definitions of each decision-making style, and asked to match each item with its relevant style from the four styles, namely, autocratic, consultative, group, and delegation. It was found that the experts were unanimous in their answer for item-styles matching and thus, was compatible with the researcher's prior item-structure model. In addition, factorial validity was performed to examine the construct validity of the scale, a matter which will be discussed in a later section.

\section{RESULTS}

This study employed both exploratory and confirmatory factor analyses procedures to examine the proposed PDMSS. The internal consistency of the scale, the extent to which items in a scale have commonalities, was measured by Cronbach's coefficient alpha.

\section{Exploratory Factor Analysis}

In this study, factors were extracted by employing Principal Component Analysis (PCA). The number of reliable factors to be extracted or retained was based primarily on two main criteria; (a) size of the factors which have an eigenvalue (the latent root) equal to or greater than 1 and (b) the scree test for eigenvalues plotted against factors must indicate a deep plot slope. Since one of the objectives of PCA is also to reduce the number of variables, thus items were omitted if they were found to be problematic in factorial complexity, uncorrelated with other variables, one variable factor, and inconsistent in terms of direction (i.e., positive and negative).

A PCA was performed through the use of the Statistical Package for Social Science (SPSS) version 12.0. In order to increase the interpretability of factors, orthogonal rotation through the varimax method was used. This rotation method produces factors which are independent of one another and thus, the information the factor provides is not redundant; since a person's score on one factor is unrelated to his/her score on another (Bryman \& Cramer, 2008). Another advantage of the varimax rotational approach is that there tends to be some high loadings which are close to \pm 1 and some loadings near 0 in each column of the matrix, and this consequently 
eases our interpretation of factors in the sense that when variablefactor correlations are (a) close to \pm 1 , this indicates a clear positive or negative correlation between the variable and the factor; or (b) close to 0 , this indicates a clear lack of association (Hair, Black, Babin, Anderson, \& Tatham, 2006).

Generally, the meaning of a factor is determined by the items, which load most highly on it. As suggested by Hair et al. (2006), factor loadings of \pm .50 or greater are considered practically significant. Thus, the larger the absolute size of the factor loading, the more significant the loading is in interpreting the factor matrix, and this is because factor loading is the correlation of the item and the factor (Hair et al., 2006). On the other hand, items which correlate less than \pm .05 with a factor were omitted from consideration. On the number of variables needed to form factors, Friendly (1995) argued that at least two variables (i.e., items) are needed to extract a common factor (by definition), however, it is better to have at least 3-5 variables believed to measure each factor. In order to increase the reliability of the factor, the present study sets the following two criteria; (1) the minimum number of items contained under a factor is four and (2) cut-off factor loadings were considered significant at or above the \pm .05 level.

The analysis with a varimax rotation extracted a three-factor solution. The resulting pattern factor matrix of the rotated solution is presented in Table 1. Based on a predetermined criterion regarding the absolute size of the factor (i.e., factor loading $\geq .50$ ), there were 5 items, namely, A1, A2, A3, A4 and A5 (see Table 1) which loaded significantly on factor III. These five items emphasize one common concern that principals do not consult any of their group members, and they always come up with the final decision themselves. Thus, this third factor was initially labeled as "autocratic decision-making."

The resulting pattern factor matrix of the rotated solution also reveals that the items which represent "consultative decisionmaking", namely, C6, C7, and C8, and items which indicate "group decision-making", namely, G9, G10, G11, G12, and G13 (see Table 1) were loaded significantly on factor I. This pattern matrix suggests a combination of these two decision styles. They highlight the fact that both principals and teachers participate in decision-making. Thus, a combination of consultative decision-making and group decision-making was labeled as "participative decision-making" which refers to the principals' keenness on involving teachers in making decisions. Snowden and Gorton (2002) view participation 
as the involvement of people in the decision-making process - be they individuals, groups, or both - who will be either affected by the decision, or in some way be responsible for implementing a decision.

The combination of consultative and group decision-making factors suggests that both styles are similar in terms of involving people in the decision making process, yet they are different in terms of the person who makes the final decision. The emphasis on people's involvement in the decision-making process implies that there is a need to achieve decision acceptance by subordinates. In this context, Maier and Gertrude (1982) propose that decisions made by individuals are meant to achieve decision acceptance or decision quality. Therefore, it is meaningful to combine these two styles and label them as "participative decision-making".

Factor II contained item D14, D15, D16, D17, D18 and D19 (see Table 1). These six significant items indicated that the principals delegate and entrust the decisional tasks to their teachers. This second factor was labeled "delegation decision-making", which reflects principals' acceptance of granting teachers the authority to decide.

The emergent 3-factor structure was verified by eigenvalue and scree test. A first empirical estimate of the number of factors to be extracted was obtained from the size of the factor eigenvalues. The above three factors had an eigenvalue greater than 1 . A second criterion to estimate the number of factors to be extracted was the scree test for eigenvalues plotted against factors. The results of the scree test indicate a three-factor solution when the plot slopes steeply downward till factor 3 before the point at which the eigenvalues appear to level off. The percentage of variance explained for factors I, II, and III was $26.35 \%, 19.57 \%$, and 14.80 , respectively. The factor matrix result shows that the common factor solution accounted for $60.72 \%$ of the total variance explained, and this was considered acceptable for a social science study. Hair et al. (2006) suggest that it is not uncommon to consider a solution for social sciences that accounts for $60 \%$ of the total variance, and in some instances even less as satisfactory.

Cronbach's coefficient alpha estimates for the scores on the sample ranged from .84 ('autocratic' subscale) to .90 ('participative' subscale) for the three dimensions. Table 2 presents the results of the internal consistency reliability, mean and standard deviation for the total and each subscale score. 


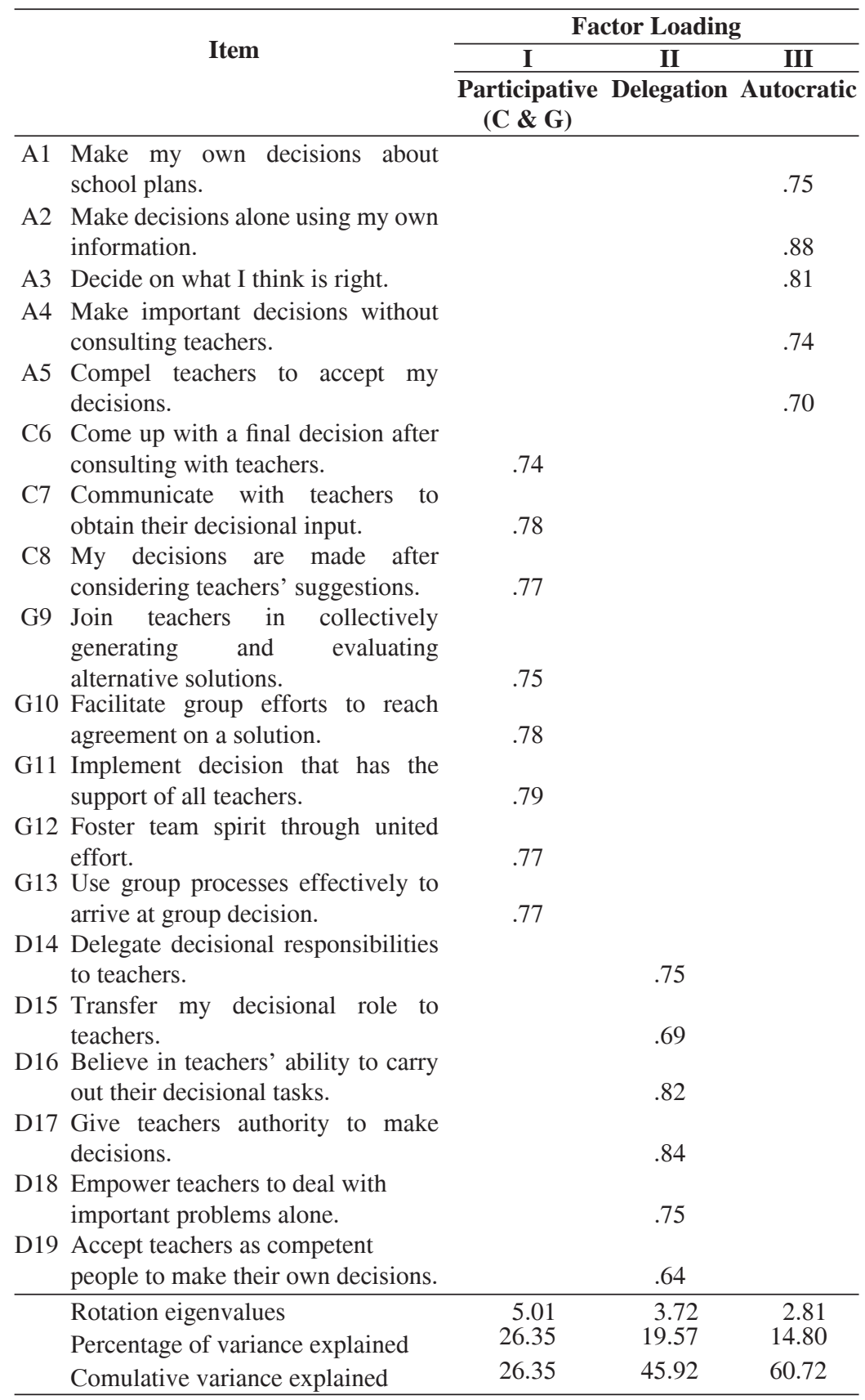

Note: $\mathrm{A}=$ Autocratic, $\mathrm{C}=$ Consultative, $\mathrm{G}=$ Group, and $\mathrm{D}=$ Delegation; only loading $>.50$ are displayed. 
Table 2. Summary Statistics for Principal Decision-Making Styles Scale, Internal Consistency Index, Mean and Standard Deviation

\# item $\quad \alpha \quad \mathbf{X} \quad$ SD

Decision-Making Styles Scale

\begin{tabular}{lcccc} 
Autocratic Decision-Making & 5 & .84 & 3.34 & 1.48 \\
Participative Decision-Making & 8 & .90 & 5.76 & 1.07 \\
Delegation Decision-Making & 6 & .85 & 3.76 & 1.51 \\
Total Scale & 19 & .86 & 4.29 & 1.35 \\
\hline
\end{tabular}

\section{Confirmatory factor analysis}

A Confirmatory Factor Analysis (CFA) was performed on the hypothesized three-common styles of principal decision-making using the Analysis of Moment Structure (AMOS) version 6.0 (Arbuckle, 2006) model-fitting program. The program seeks to optimally match the observed and theoretical factor structures for collected data in order to determine the "goodness of fit" of the predetermined factor model. Maximum likelihood as the method of estimation was employed to generate estimates of parameters in the measurement model.

The result of CFA in the first measurement model shows inadequate model fit as most of the fit indices fall below the recommended value. To improve model fit or its correspondence to the underlying theory, this study engaged in model re-specification through the process of correlating some measurement errors. Examination of the modification indices (MI) suggested that estimation of some correlated errors would improve the fit of the model. The correlated errors indicated that some of these items shared specific variance that was not part of the latent variable. Though correlating errors is commonly used as a means of reducing chi-square that would occur if the coefficient were estimated, this technique also indirectly results in increasing other fit indices' values. Examination of the MI suggested these correlations of errors, namely the error in measuring the ninth item (e9) was correlated with the error in measuring the tenth item (e10). Likewise, on the basis of similar examination, the model suggested the estimation of 
covariance between e11 and e12, e12 and e13, e13 and e14, and e18 and 19 .

The chi-square $\left(\chi^{2}\right)$, degree of freedom (df) and probability level (p) was achieved at 215.005, 144, and .000, respectively. The chi-square test should not be significant if there is a good model fit. Since, a chi-square test is highly sensitive to sample size, and its value for the present study indicates that the model did not adequately fit the data, it is thus important to examine the other fit indices. Reporting multiple fit indices are necessary for the evaluation of model fit of the proposed models. Hair et al. (2006) posit that "multiple fit statistics should be reported to help understand how well a model truly fits" (p. 835). The fit of the measurement in the present study was assessed by means of seven indices, namely, minimum sample for discrepancy divided by degree of freedom (CMINDF), incremental fit index (IFI), normed fit index (NFI), Tucker-Lewis index (TLI), comparative fit index (CFI), goodness of fit index (GFI), and the root mean square error of approximation (RMSEA).

The fit indices of the model increased after correlating errors. The final evaluation resulted in a model with a satisfactory fit (see Figure 1). The CMINDF (1.493) and RMSEA (.064) fall well below the maximum recommended value of 5 and .08 , respectively. The other fit indices are .935 (IFI), .827 (NFI), .921 (TLI), .934 (CFI), and .847 (GFI). These indices can take on values from 0 to 1 ; the closer the value is to 1 , the better the fit of the model. According to Stevens (2002), a value of .90 is recommended, and this value is used by many researchers as an indication of a good fit. By this criterion, the present model is accepted, because the value for the above indices exceeds the recommended critical value of .90 , with the exception of NFI and GFI. Though the latter two indices fall short of the recommended value, their acceptability is marginal. Thus, a conclusion could be made that the overall model goodness-of-fit results lend reasonable support for confirmation of the proposed model of three decision-making styles. Correlation among factors were insignificant and trivial, which ranged from 0.03 (autocratic and participative) to 0.14 (autocratic and delegation). Thus, it suggests that each subscale is relatively independent of the other scales. 


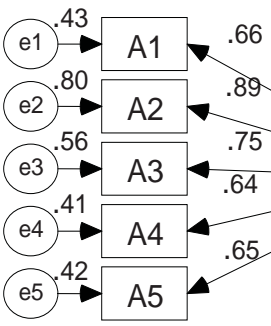

\section{Autocratic}
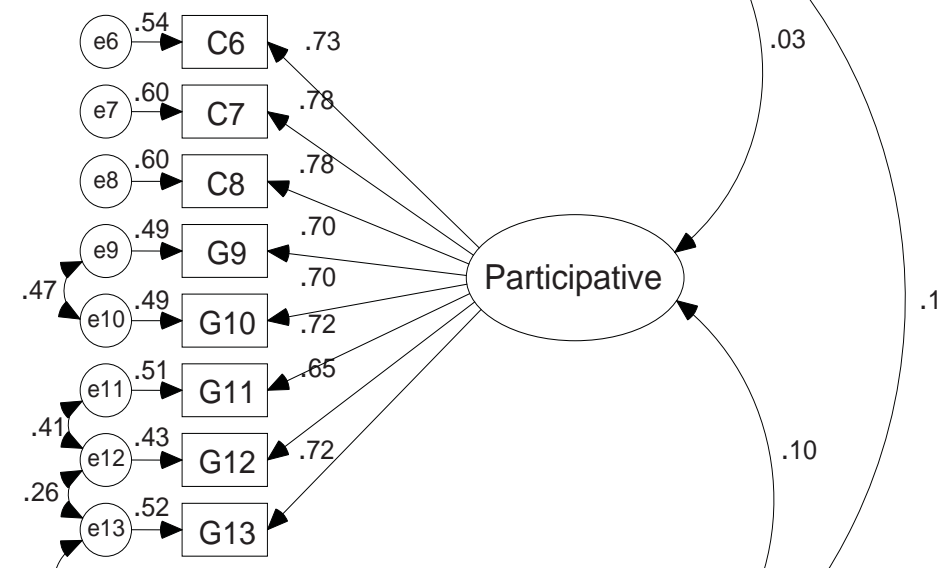

.40
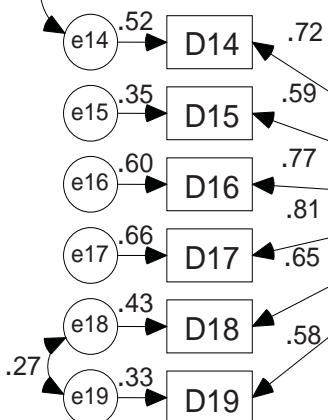

Figure 1. A Measurement Model for Principal Decision-Making Styles Goodness of Model Fit: CMINDF=1.493, IFI=.935, $N F I=.827, T L I=.921, C F I=.934, G F I=.847$ and $R M S E A=.064$

\section{CONCLUSION}

This study presents the development and the construct validation of an instrument designed to measure principal decision-making styles. Four decision-making styles were postulated a priori and based on 
Vroom and Yetton's (1973) decision-making model. These styles are autocratic, consultative, group, and delegation. With this frame of reference in mind, behaviorally phrased items were then developed. Based on the experts' examination, the scale has face validity and logical content validity.

Factorial validity of the scale was also evaluated through the use of factor analysis and the examination of the factor loadings. The results of pattern factor matrix suggest a combination of consultative decision-making and group decision-making and thus, yield an overall of three reliable decision-making styles (i.e., autocratic, participative, and delegation) for the Malaysian sample, which is inconsistent with the previous theoretical proposal of the four styles model. The combination of the above two styles was labeled as 'participative decision-making', whose items indicate a common behavior of the principal's conscious involvement of teachers in making decision. This participative style has been previously identified by decision-making style researchers (e.g., Cheng, 2008; Don \& Charles, 2008; and Femke, Peter, Reinoud \& Meta, 2009), and it has been considered an influential construct affording a higher possibility of success in school decision-making. The emergent three decision styles were further confirmed using confirmatory factor analysis when the overall indices indicate a good model fit.

The combination of the above two styles seems to imply that Malaysian school principals place much emphasis on their subordinates' involvement in the decision-making process. This emphasis is consistent with the current plan of education in Malaysia which aims to give teachers proper recognition, and to increase their job satisfaction by involving them in the decision-making process (Hassan, 2002). When teachers are involved in the decision-making process, they obtain professional satisfaction. In this context, Cheng (2008) reported that teachers' involvement in decision-making will increase their job satisfaction, and this possibly becomes a stimulating factor that sustains teachers in their profession, as is intended by the plan. Additionally, Wilson (1997) reported that delegation decisionmaking brought about higher efficacy and motivation.

On the other hand, autocratic decision-making appeared to have negative consequences on both self-efficacy and motivation (Leadership Management Development Center [LMDC], 1997). These negative consequences are so vivid in the Malaysian educational context where an increasing number of teachers change their profession (Hassan, 2002). In spite of the fact that there are 
still some autocratic practices in the Malaysian educational context, there is a noticeable shift from this style to a participative decisionmaking and delegation decision-making style, which in turn can increase subordinates' satisfaction and enhance their self efficacy and motivation.

One major contribution of this study is that this scale helps to resolve the lack of an available instrument for measuring principal decision-making styles. Decision-making style has been previously developed focusing on theoretical understanding and conceptual definitions (e.g., Hunt, Krzystofiak, Meindl, \& Yousry 1989; Hoy \& Tarter, 1993) rather than the construct validation of its measure. This existing gap has called for an assessment of the construct validation of decision-making styles scale.

Face examinations and factorial analyses presented in this study suggest that the scale shows promise as a reliable and valid instrument for measuring principal decision-making styles. Therefore, this scale can be used by Malaysian researchers who are interested in studying this construct or its relationship with other constructs. Naturally, further research using different samples is needed for cross-validated evidence.

\section{REFERENCES}

Arbuckle, J. L. (2006). AMOS 6.0 (Computer software). Chicago: Smallwaters.

Blair, G. M. (2004). The art of delegation. Retrieved March 26, 2009, from http://www.see.ed.ac.uk/ gerard/Management/ art5.html.

Bogler, R. (2001). The influence of leadership style on teacher job satisfaction. Educational Administration Quarterly, 37 (5), 662-683.

Bryman, A. \& Cramer, D. (2008). Quantitative data analysis with SPSS 14, 15 and 16: A guide for social scientists. New York: Routledge.

Cheng, C. K. (2008). The effect of shared decision-making on the improvement in teachers' job development. New Horizons in Education, 56 (3), 31-46.

DeVellis, R. F. (2003). Scale development: Theory and application. Newbury Park: Sage Publications. 
Don, L. \& Charles, R. F. (2008). Faculty perceptions of shared decision-making and the principal leadership behavior in secondary school in a large urban district. Education, 128 (4), 630-644.

Driver, M. J., \& Mock, T. J. (1975). Human information processing, decision style theory, and accounting information systems. Accounting Review, 50, 490-508.

Dunham, J. (1995). Developing effective school management. New York: Routledge.

Edwards, C. E., (2004). Classroom discipline and management (4th ed.). New Jersey: Prentice-Hall, Inc.

Femke, G., Peter, C.S., Reinoud, S., \& Meta, K. (2009). The effect of teacher psychological and school organizational and leadership factors on teachers' professional learning in Dutch schools. Elementary School Journal, 109 (4), 406-427.

Friedman, I. (1985). Decision-making style of school principal: A questionnaire. Jerusalem: Institute of Henrieta Sald.

Friendly, M. (1995). Planning a factor analytic study. Retrieved March 25, 2009, from http://www.psych.yorku.ca/lab/ psy6140/fa/facplan.htm.

Gallagher, T. J. (2002). Employee participation in decision making in extension: A ladder of participation to reduce cynicism. Retrieved March 26, 2009, from http://www.joe.org/ joe/2002october/comm2.php.

George, J. M., \& Jones, G. R. (2000). Essentials of managing organizational behavior. New Jessey: Prentice Hall.

Hair, J. F., Black, W.C., Babin, B. J., Anderson, R. E., \& Tatham, R. L. (2006). Multivariate data analysis (6th ed.). New Jersey: Pearson Prentice Hall.

Harren, V. A. (1979). A model of career decision making for college students. Journal of Vocational Behavior, 14, 119-133.

Hassan Said (2002). Education in Malaysia: Enhancing accessibility, capability and quality. Retrieved August 13, 2009, from http://www.worldedreform.com/intercon/kedre15.htm.

Hoy, W. K., \& Tarter, C. J. (1993). A normative model of shared decision making. Journal of Educational Administration, 31, 4-19.

Hunt, R. G., Krzystofiak, F. J., Meindl, J. R., \& Yousry, A. M. (1989). Cognitive style and decision making. Organizational Behavior and Human Decision Processes, 44, 436-453. 
Jung, K. (1971). Psychological types. New Jersey: Princeton University Press.

Leadership Management Development Center [LMDC]. (1997). Decision making styles. Retrieved August 13, 2009, from http://www.leadershipmanagement.com/html-files/decision. htm.

Maier, R. F., \& Gertrude, C. V. (1982). Psychology in industrial organization (5th ed.). New York: Houghton Mifflin.

McKeeney, J. L., \& Keen, P. (1974). How managers' minds work [Electronic version]. Harvard Business Review, May-June, 79-90.

Myers, I. B. (1975). Manual: The Myers-Briggs type indicator. California: Consulting Psychologists Press.

Myers, I. B., \& McCaulley, M. (1985). Manual: A guide to the development and use of the Myers-Brigs type indicator. California: Consulting Psychologists Press.

Nelson, D. L., \& Quick, J.C. (2009). Organizational behavior: Science, the real world, and you (6th ed.). United States: South-Western Cengage Learning.

Nye, K., \& Capelluti, J. (2003). The ABCS of decision making [Electronic version]. Principal Leadership, 3 (9), 8-9.

Owen, R. G. (2004). Organizational behavior in education: Adaptive leadership and school reform (8th ed.). Boston: Pearson.

Pashiardis, P. (1993). Group decision making: The role of the principal. International Journal of Educational Management, 7 (2), 8-11.

Schweiger, D. M., \& Jago, A. G. (1982). Problem-solving styles and participative decision making. Psychological Reports, 50, 1311-1316.

Scott, S. G., \& Bruce, R. A. (1995). Decision-making style: The development and assessment of a new measure. Educational and Psychological Measurement, 55 (5), 818-831.

Snowden, P. E., \& Gorton, R. A. (2002). School leadership and administration: Important concepts, case studies, and simulations. New York: Mc Graw Hill.

Stevens, J. (2002). Applied multivariate statistics for the social sciences (4th ed.). New Jersey: Lawrence Erlbaum Associates.

Tannenbaum, R., \& Schmidt, W. H. (1973). How to choose a leadership pattern [Electronic version]. Harvard Business Review, May-June, 162-180. 
Ubben, G. C., Hughes, L.W., \& Norris, C. J. (2001). The principal: Creative leadership for effective schools (4th ed.). Boston: Allyn and Bacon.

Vroom, H. V., \& Jago, A. G. (1988). The new leadership: Managing participation in organization. New Jersey: Prentice-Hall.

Vroom, H. V., \& Yetton, P. W. (1973). Leadership and decisionmaking. Pittsburgh: University of Pittsburgh Press.

Wilson, W. (1997). Delegation. Retrieved August, 13, 2009, from http://www.see.ed.ac.uk/ gerard/ MENG/ME96/Documents/ Aspects/delegate.html. 
